ORIGINAL ARTICLE ARTIGO ORIGINAL

\title{
Cost-effectiveness of atypical antipsychotics for the treatment of schizophrenia
}

\author{
Custo-efetividade de antipsicóticos atípicos \\ para o tratamento da esquizofrenia \\ André Soares Santos' ${ }^{1}$ Carlos Eduardo Leal Vidal2,3, Cristina Mariano Ruas Brandão' \\ DOI: $10.21115 / J B E S . v 8 . n 3 . p 204-215$
}

\section{Keywords:}

schizophrenia, antipsychotic agents, cost-benefit analysis, health economics, mental health

\section{Palavras-chave:}

esquizofrenia, antipsicóticos, análise de custo-benefício, economia da saúde, saúde mental

\begin{abstract}
Objectives: To conduct a cost-effectiveness analysis of second-generation antipsychotics (SGA) for schizophrenia in Brazil. Methods: A Markov model was built for the evaluation of the cost-effectiveness of risperidone, quetiapine, ziprasidone and olanzapine in the Brazilian public health system. The time horizon of the analysis was 18 months. The effectiveness was measured in terms of discontinuation of treatment for any cause and the costs were measured in 2014 BRL and USD. Results: Olanzapine was found to be dominant over the other strategies. The analysis of the optimal choice indicated that olanzapine was recommended, considering a null Willingness-to-Pay (WTP), in 51.8\% of the trials. The increase in values of WTP makes the chance of olanzapine to be optimal increase, achieving 100\% at approximately 252.00 BRL (114.03 USD) per month of effective treatment. The Probabilistic Sensitivity Analysis (PSA), has shown olanzapine to be optimal in $49.6 \%$ of the trials, considering a null WTP. The chance of optimality of olanzapine achieved 100\% at a WTP of 364,00 BRL (164.71 USD) per month of effective treatment. The results have shown the importance of prescription costs of olanzapine and hospitalization costs for the Incremental Cost-Effectiveness Ratio (ICER). Conclusion: Olanzapine was found to be dominant over risperidone, quetiapine and ziprasidone, in Brazil. The sensitivity analysis has shown that the cost-effectiveness relationship between olanzapine and risperidone can be modified by the price of purchase of olanzapine. Due to the low values of ICER showed in the sensitivity analysis and PSA, olanzapine can be considered the most cost-effective strategy evaluated.
\end{abstract}

\section{RESUMO}

Objetivos: Este estudo realizou uma análise de custo-efetividade entre antipsicóticos de segunda geração (SGA) para a esquizofrenia no Brasil. Métodos: Foi construído um modelo de Markov baseado na prática clínica, dados de literatura e bases de dados governamentais, comparando custos e efetividade da risperidona, quetiapina, ziprasidona e olanzapina no sistema público de saúde do Brasil. O horizonte temporal da análise foi 18 meses. O desfecho utilizado para avaliação da efetividade foi a descontinuação do tratamento por qualquer causa e os custos foram medidos em BRL e USD (2014). Resultados: A olanzapina foi considerada dominante sobre as outras estratégias avaliadas. A análise indicou que a olanzapina foi considerada ótima, com disposição a pagar (WTP) nula, em 51,8\% dos ensaios. O aumento progressivo dos valores de WTP eleva a chance de a olanzapina ser considerada ótima, alcançando 100\% em cerca de 252.00 BRL (114,03 USD) por mês de

\footnotetext{
Received on: 06/22/2016. Approved for publication on: 11/18/2016.

1. Department of Social Pharmacy, Universidade Federal de Minas Gerais (UFMG), Belo Horizonte, MG, Brazil.

2. Department of Psychiatry, Faculdade de Medicina de Barbacena (FAME), Barbacena, MG, Brazil.

3. Barbacena Psychiatric Hospital Centre, Fundação Hospitalar do Estado de Minas Gerais (FHEMIG), Barbacena, MG, Brazil.

This study was funded by the Brazilian research promoting organizations Conselho Nacional de Desenvolvimento Cientifico e Tecnológico (CNPq) and Fundação de Amparo à Pesquisa do Estado de Minas Gerais (FAPEMIG). No pharmaceutical industries contributed with resources for this study. The authors declare to have no conflicts of interest that could influence the results of this study. This study was approved by the ethics committee of Fundação Hospitalar do Estado de Minas Gerais (FHEMIG) under CAAE protocol: 01934812.8.0000.5119.

This study was not yet presented in any event. It was, though, submitted to the Fórum Brasileiro de Assistência Farmacêutica e Farmacoeconomia, that will happen From July $26^{\text {th }}$ to $29^{\text {th }}$ in Salvador, Brazil. It is original and was not submitted to any other journal. All the authors have collaborated with the final text of the manuscript.

Corresponding author: André Soares Santos. Rua Maria Martins Guimarães, 122, ap. 101, Sagrada Família. Belo Horizonte, MG, Brazil. CEP: 31035-10. Phone: +55 (31) 99180-8788. E-mail: andressantos111@gmail.com
} 
tratamento efetivo. Na Análise de Sensibilidade Probabilística (PSA), a olanzapina foi considerada ótima em 49,6\% dos ensaios, considerando WTP nula. A chance de a olanzapina ser a escolha ótima atingiu 100\% em um WTP de 364,00 BRL (164.71 USD) por mês de tratamento efetivo. Os resultados mostram a importância dos custos de prescrição da olanzapina e de hospitalização para a Razão de Custo-Efetividade Incremental (RCEI). Conclusão: A olanzapina mostrou-se dominante quando comparada a risperidona, quetiapina e ziprasidona, no Brasil. Devido aos baixos valores de RCEl encontrados na análise de sensibilidade e PSA, a olanzapina pode ser considerada a estratégia mais custo-efetiva avaliada.

\section{Introduction}

Schizophrenia is a debilitating chronic condition characterized by disorders in thought, affection and behavior. It is costly to society due to its long course, high occurrence of comorbidities, necessity of hospitalizations and lack of a universally effective pharmacological treatment. Its prevalence is estimated between 0.3 and 1\% worldwide (Mari \& Leitão, 2000; Daltio et al., 2007; Messias et al., 2007). The disease has high costs associated to the loss of productivity (Genduso \& Haley, 1997; Behan et al., 2008) and the most relevant direct cost is hospitalization. Drug prescriptions seem to contribute with only a small portion of the total costs (Genduso \& Haley, 1997; Knapp et al., 2004; Jones et al., 2006). The pharmacotherapy of schizophrenia is based on antipsychotic drugs, but their efficacy is limited, culminating in discontinuation of treatment, relapses and hospitalizations (APA, 1994; Stroup et al., 2006; APA, 2013; Brazil 2013; NICE, 2014). Drugs can, however, influence hospitalization rates and productivity, becoming very important for the economics of schizophrenia (Lieberman et al., 2005; Liu-Seifert et al., 2011). Studies that evaluate the efficacy, effectiveness and safety of antipsychotics found that the results depend on the outcome of choice and medication doses, but demonstrated that there might be differences between drugs (Breier et al., 2005; Lieberman et al., 2005; McEvoy et al., 2006; Stroup et al., 2006; Stroup et al., 2007).

Knapp et al. (2004) conducted a systematic review of Cost-of-lllness studies on schizophrenia and concluded that these costs are high, variable in different locations, relevant to the health system and that the intangible costs per se already justify investments in research and development of new treatments. McEvoy (2007) reported that in the United States of America (USA), between 1991 and 2002, the hospitalization costs decreased, but the costs of outpatient treatment and medication increased. The drop of inpatient costs is explainable by changes of policy and the availability of new drugs for the treatment of schizophrenia. In fact, there was a reduction in psychiatric beds worldwide in the last few decades as a result of reforms in mental health care concepts and practices (Lay et al., 2007). But, despite that, hospitalization costs are still the main direct cost driver of schizophrenia. Reducing length of stay and occurrence of relapse might be important to reduce schizophrenia treatment costs (Genduso \& Haley, 1997; Jones et al., 2006; Daltio et al., 2007). The adverse effects profile of the drugs can be very different, especially considering the higher risks of extrapyramidal syndrome with first-generation antipsychotics (FGA) and risperidone, metabolic syndrome with olanzapine and clozapine, hyperprolactinemia with risperidone and agranulocitosis with clozapine (Breier et al., 2005; Lieberman et al., 2005; McEvoy et al., 2006).

Considering the limited effectiveness of the pharmacological treatment of schizophrenia, associated with the high costs of the disease and the progressive higher expenditures with medication by health systems, an evaluation of the costeffectiveness profile of antipsychotic drugs is necessary to allow an adequate choice of pharmacotherapy for the patients, in accordance with the financial reality of health systems (WHO, 1998; Brandão et al., 2011; Machado et al., 2011). The aim of this study is to conduct a cost-effectiveness analysis of second-generation antipsychotics (SGA) for schizophrenia in Brazil.

\section{Methods}

This study evaluated the cost-effectiveness relationship between the SGAs risperidone, quetiapine, ziprasidone and olanzapine, in the Brazilian public health system, through a Markov model, built in Treeage Pro ${ }^{\oplus} 2009$ and based in clinical practice, literature data and governmental databases. Clozapine was not included because it is considered the last therapeutic resource, reserved for refractory patients (Rosenheck et al., 2006; Brazil, 2013; NICE, 2014). As oriented by the Brazilian Ministry of Health, the analysis adopts the perspective of the health system (Brazil, 2009). The time horizon of the analysis was 18 months, divided into three-month cycles. There is no robust evidence that the extrapolation of effectiveness data reflects the long-term effectiveness of antip- 
sychotics or their effect on the course of the disease in real life (Garcia-Ruiz et al., 2012). This time horizon was chosen to suit the Clinical Antipsychotics Trials of Intervention Effectiveness (CATIE), main source of effectiveness data (Lieberman et al., 2005; McEvoy et al. 2006; Stroup et al., 2006; Stroup et al., 2007). CATIE was a pragmatic multicenter randomized clinical trial funded by the National Institute of Mental Health (NIMH) of the USA. Patients were initially randomized for groups of treatment in use of perphenazine, risperidone, quetiapine, ziprasidone and olanzapine. The main outcome was discontinuation of treatment for any cause, but hospitalizations, side effects and PANSS and CGI scales scores were also evaluated (Lieberman et al., 2005; McEvoy et al., 2006; Stroup et al., 2006; Stroup et al., 2007). CATIE was used before as a source of data for economic evaluations (Rosenheck et al., 2006; Davies et al., 2007; Obradovic et al., 2007; Furiak et al., 2009; McIntyre et al., 2010; O'Day et al., 2013; Park \& Kuntz 2014).

The cessation or change of the pharmacological treatment are recurrent occurrences and constitute a serious problem for schizophrenic patients. The outcome used for effectiveness evaluation was discontinuation of treatment for any cause, in accordance with CATIE's assessment. The discontinuation of treatment allows the integration of the judgment of patients and doctors in terms of efficacy, safety and tolerability in a global measure of effectiveness that reflects the therapeutic benefits in contrast with the undesirable effects of the treatment (Lieberman et al., 2005). The data of discontinuation of treatment for any cause were extracted from the Kaplan-Meier curve presented by Lieberman et al. (2005) with the software Digitazelt ${ }^{\circledast}$ (Figure 1).

In the model, patients initiate the treatment with one of the evaluated drugs and can die, discontinue or remain in the treatment in each cycle. Discontinuation of treatment was considered an absorbing state and no costs or effectiveness were computed. If the patient remains in treatment in each trimester, the model considers that the treatment was effective and three points are added to the effectiveness analysis, one for each month. For the Half-Cycle Correction, 1.5 points are added to the effectiveness analysis at the last cycle for patients in "Discontinuation" or "Death" states (Figure 2). The model was analyzed through a First-Order Monte Carlo Simulation, using 1000 cohorts repeated 1000 times to report the average, to assess the variation in drugs purchase prices. Mortality data was calculated by antipsychotic with data from Instituto Brasileiro de Geografia e Estatística (IBGE), McGrath et al. (2008) and Tiihonen et al. (2009). Hospitalization rates and adverse effects probability were extracted from Lieberman et al. (2005) (Table 1).

The costs identified for inclusion in the model were: antipsychotic prescription, inpatient treatment and adverse effects treatment. The amount of each service or product was based on literature data or clinical practice (Table 2). The most usual treatment for hyperprolactinemia is the discontinuation of the antipsychotic, so the cost of it was not included

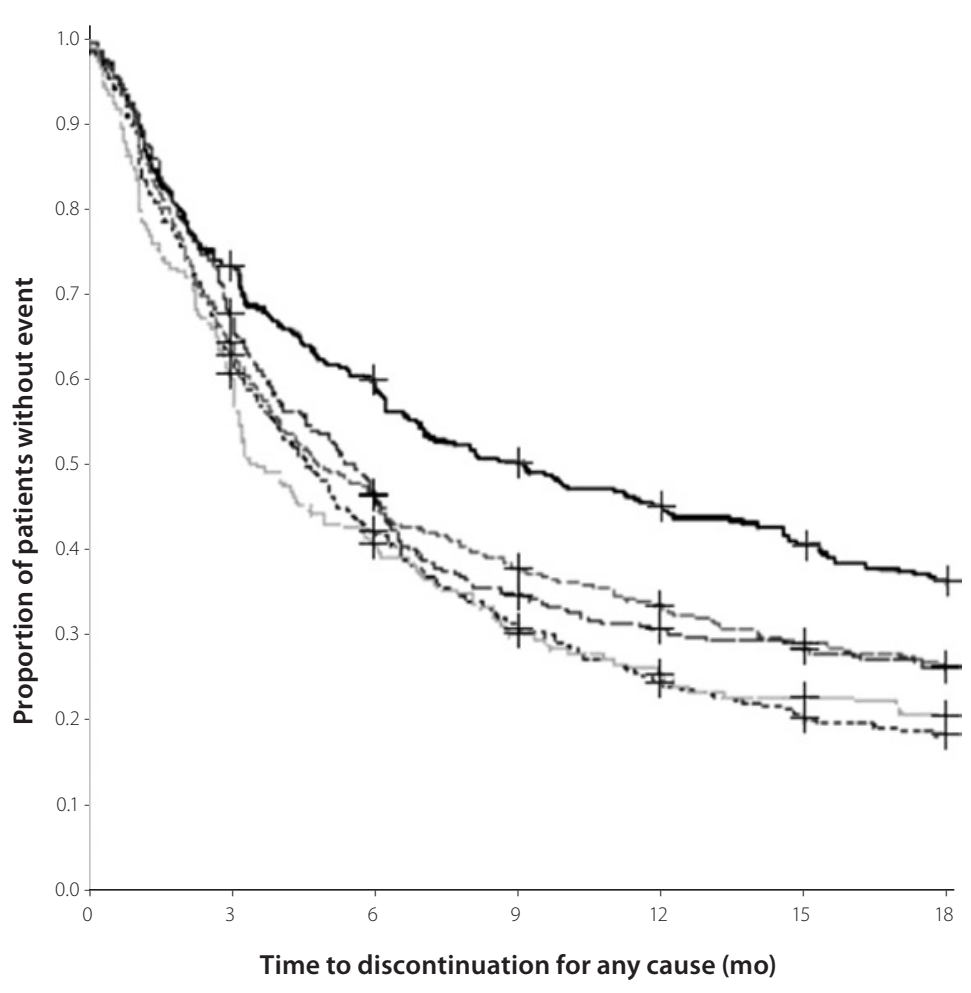

\begin{tabular}{|c|c|}
\hline $\begin{array}{c}\text { x-range: } \\
0.00 ; \\
\text { scale: linear }\end{array}$ & 18.6 \\
\hline $\begin{array}{c}\text { y-range: } \\
0.00 ; \\
\text { scale: linear }\end{array}$ & 1.00 \\
\hline $\begin{array}{l}\text { points: } 30 \\
\text { no sorting }\end{array}$ & \\
\hline 2.99 & 0.607 \\
\hline 2.99 & 0.629 \\
\hline 2.99 & 0.644 \\
\hline 2.99 & 0.678 \\
\hline 2.99 & 0.733 \\
\hline 5.99 & 0.408 \\
\hline 5.99 & 0.423 \\
\hline 5.99 & 0.464 \\
\hline 5.99 & 0.467 \\
\hline 5.99 & 0.600 \\
\hline 9.02 & 0.364 \\
\hline 9.02 & 0.309 \\
\hline 9.02 & 0.347 \\
\hline 9.02 & 0.379 \\
\hline 9.02 & 0.502 \\
\hline 12.0 & 0.245 \\
\hline 12.0 & 0.255 \\
\hline 12.0 & 0.308 \\
\hline 12.0 & 0.335 \\
\hline 12.0 & 0.451 \\
\hline 15.0 & 0.204 \\
\hline 15.0 & 0.228 \\
\hline 15.0 & 0.284 \\
\hline 15.8 & 0.291 \\
\hline 15.0 & 0.465 \\
\hline 18.0 & 0.184 \\
\hline 18.0 & 0.206 \\
\hline 18.0 & 0.262 \\
\hline 18.0 & 0.264 \\
\hline 18.0 & 0.363 \\
\hline
\end{tabular}

Figure 1. Kaplan-Meier curve of the discontinuation of treatment for any cause (Lieberman et al. (2005) modified). 


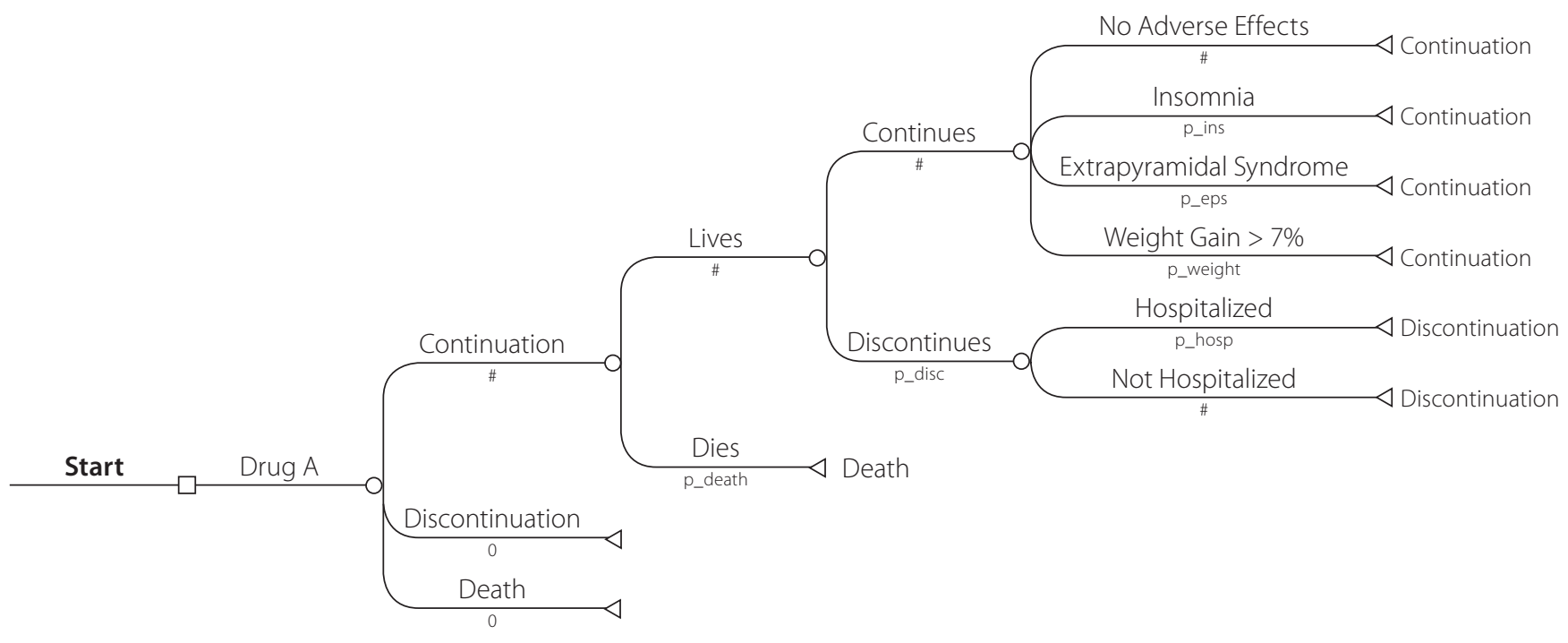

Figure 2. Schematic representation of the Markov Cycle Tree.

Table 1. Probabilities used for the construction of the Markov model per cycle

\begin{tabular}{|c|c|c|c|c|}
\hline Drug & Value & \multicolumn{2}{|c|}{ Interval } & Reference \\
\hline \multicolumn{5}{|c|}{ Mortality probability } \\
\hline Risperidone & 0,005601 & 0,004681 & 0,006724 & IBGE; McGrath (2008); Tiihonen (2009) \\
\hline Quetiapine & 0,006122 & 0,004761 & 0,007892 & IBGE; McGrath (2008); Tiihonen (2009) \\
\hline Ziprasidone & 0,006483 & 0,005561 & 0,007529 & IBGE; McGrath (2008); Tiihonen (2009) \\
\hline Olanzapine & 0,003883 & 0,003206 & 0,004641 & IBGE; McGrath (2008); Tiihonen (2009) \\
\hline \multicolumn{5}{|c|}{ Hospitalization probability } \\
\hline Risperidone & 0,203804 & 0,183424 & 0,224185 & Lieberman et al. (2005) \\
\hline Quetiapine & 0,245098 & 0,220588 & 0,269608 & Lieberman et al. (2005) \\
\hline Ziprasidone & 0,226700 & 0,20403 & 0,24937 & Lieberman et al. (2005) \\
\hline Olanzapine & 0,172684 & 0,155416 & 0,189953 & Lieberman et al. (2005) \\
\hline \multicolumn{5}{|c|}{ Weight gain $>7 \%$ probability } \\
\hline Risperidone & 0,14 & 0,126 & 0,154 & Lieberman et al. (2005) \\
\hline Quetiapine & 0,16 & 0,144 & 0,176 & Lieberman et al. (2005) \\
\hline Ziprasidone & 0,07 & 0,063 & 0,077 & Lieberman et al. (2005) \\
\hline Olanzapine & 0,30 & 0,27 & 0,33 & Lieberman et al. (2005) \\
\hline \multicolumn{5}{|c|}{ Insomnia probability } \\
\hline Risperidone & 0,24 & 0,216 & 0,264 & Lieberman et al. (2005) \\
\hline Quetiapine & 0,18 & 0,162 & 0,198 & Lieberman et al. (2005) \\
\hline Ziprasidone & 0,30 & 0,27 & 0,33 & Lieberman et al. (2005) \\
\hline Olanzapine & 0,16 & 0,144 & 0,176 & Lieberman et al. (2005) \\
\hline \multicolumn{5}{|c|}{ Extrapyramidal syndrome probability } \\
\hline Risperidone & 0,31 & 0,279 & 0,341 & Lieberman et al. (2005) \\
\hline Quetiapine & 0,22 & 0,198 & 0,242 & Lieberman et al. (2005) \\
\hline Ziprasidone & 0,27 & 0,243 & 0,297 & Lieberman et al. (2005) \\
\hline Olanzapine & 0,27 & 0,243 & 0,297 & Lieberman et al. (2005) \\
\hline
\end{tabular}


Table 2. Costs associated with the treatment of schizophrenia 2014 BRL (USD)

\begin{tabular}{|c|c|c|c|c|}
\hline \multicolumn{2}{|l|}{ Cost } & \multicolumn{2}{|c|}{ Interval } & \multirow{2}{*}{$\begin{array}{l}\text { Reference } \\
\text { BPS; Lieberman et al. (2005); Stroup et al., 2006; } \\
\text { Stroup et al. (2007); McEvoy et al. (2006) }\end{array}$} \\
\hline \multirow{4}{*}{ Drugs } & $\begin{array}{l}\text { Risperidone } \\
4 \text { mg/day }\end{array}$ & $\begin{array}{l}\$ 25.20 \\
(\$ 11.40)\end{array}$ & $\begin{array}{l}\$ 46.26 \\
(\$ 20.93)\end{array}$ & \\
\hline & $\begin{array}{l}\text { Quetiapine } \\
600 \text { mg/day }\end{array}$ & $\begin{array}{l}\$ 245.70 \\
(\$ 111.18)\end{array}$ & $\begin{array}{l}\$ 245.70 \\
(\$ 111.18)\end{array}$ & $\begin{array}{l}\text { BPS; Lieberman et al. (2005); Stroup et al. (2006); Stroup et al. (2007); } \\
\text { McEvoy et al. (2006); Newcomer et al. (2009); Sirota et al. (2006); } \\
\text { Sacchetti et al. (2008); Riedel et al. (2007) }\end{array}$ \\
\hline & $\begin{array}{l}\text { Ziprasidone } \\
120 \mathrm{mg} / \text { day }\end{array}$ & $\begin{array}{l}\$ 1,115.10 \\
(\$ 504.57)\end{array}$ & $\begin{array}{l}\$ 1,162.58 \\
(\$ 526.05)\end{array}$ & $\begin{array}{l}\text { BPS; Lieberman et al. (2005); Stroup et al. (2006); } \\
\text { Li et al. (2012); Ou et al. (2013); Breier et al. (2005) }\end{array}$ \\
\hline & $\begin{array}{l}\text { Olanzapine } \\
20 \text { mg/day }\end{array}$ & $\begin{array}{l}\$ 60.30 \\
(\$ 27.29)\end{array}$ & $\begin{array}{l}\$ 283.50 \\
(128.28)\end{array}$ & $\begin{array}{l}\text { BPS; Lieberman et al. (2005); Stroup et al. (2006); Stroup et al. (2007); } \\
\text { McEvoy et al. (2006); Li et al. (2012); Ou et al. (2013); } \\
\text { Tollefson et al. (2001); Shafti et al. (2014) }\end{array}$ \\
\hline \multicolumn{2}{|l|}{ Hospitalization } & $\begin{array}{l}\$ 12,025.13 \\
(\$ 5,441.24)\end{array}$ & $\begin{array}{l}\$ 14,697.38 \\
(\$ 6,650.40)\end{array}$ & Daltio et al. (2011) adjusted for 2014 values \\
\hline \multirow{3}{*}{$\begin{array}{l}\text { Adverse } \\
\text { effects }\end{array}$} & Weight gain & $\begin{array}{l}\$ 18.90 \\
(\$ 8.55)\end{array}$ & $\begin{array}{c}\$ 23.10 \\
(\$ 10.45)\end{array}$ & Oliveira (2014) \\
\hline & EPS & $\begin{array}{l}\$ 14.40 \\
(\$ 6.52)\end{array}$ & $\begin{array}{l}\$ 19.53 \\
(\$ 8.84)\end{array}$ & BPS \\
\hline & Insomnia & $\begin{array}{c}\$ 9.63 \\
(\$ 4.36)\end{array}$ & $\begin{array}{c}\$ 15.46 \\
(7.00)\end{array}$ & BPS \\
\hline
\end{tabular}

in the analysis. Sedation and somnolence are not always an undesirable effect of antipsychotic treatment. Lieberman et al. (2005) did not find significant difference between drugs in terms of suicide attempts or suicide ideation. There was no difference between groups in Qtc interval changes. Agranulocytosis happens mainly with clozapine, leading to drug discontinuation. The costs of laboratory tests and ambulatory treatment were considered equal to all drugs evaluated and were not included in the model, as the costs of drugis dispensable. Insomnia in schizophrenic patients is treated with the association of drugs. For the estimation of costs of insomnia, it was considered that half of the patients had an anticholinergic drug (prometazine) and half a benzodiazepine (clonzepam) prescribed. The cost of extrapyramidal syndrome was estimated with the association of biperiden, $2 \mathrm{mg} /$ day. The average cost of hospitalization was considered equivalent for all evaluated treatments and extracted from Rodrigues (2015). The cost of weight gain was estimated from the data of treatment costs of obesity in Brazil, as studied by Oliveira (2013).

The purchase price of medication was extracted from the Brazilian Ministry of Health's database, Banco de Preços em Saúde (BPS). BPS is a tool that registers purchase prices of drugs and health products with information from public and private institutions. The cost per Markov cycle was obtained with the mean dose reported in the literature (Tollefson et al., 2001; Breier et al., 2005; Lieberman et al., 2005; McEvoy et al., 2006; Sirota et al., 2006; Stroup et al., 2006; Riedel et al., 2007; Stroup et al., 2007; Sacchetti et al., 2008; Newcomer et al., 2009; Li et al., 2012; Ou et al., 2013; Shafti \& Gilanipoor, 2014). All cost data was adjusted for 2014 BRL and USD (1 USD =
2.21 BLR in 12/31/2014). A discount rate of 5\% was adopted for costs and benefits as indicated by the Brazilian Ministry of Health (Brazil, 2009).

A deterministic univariate sensitivity analysis was conducted in the parameters hospitalization costs, discount rate and adverse events cost, and presented in a tornado diagram. Additionally, a probabilistic sensitivity analysis (PSA) was conducted. The uncertainty in probabilities and hospitalization, weight gain, insomnia and extrapyramidal syndrome costs were evaluated by the variation of $\pm 10 \%$ in the point estimate.

This study was approved by the ethics committee of Fundação Hospitalar do Estado de Minas Gerais (FHEMIG) under CAAE protocol: 01934812.8.0000.5119.

\section{Results}

Olanzapine was considered the least costly option in the cost analysis, followed by risperidone, ziprasidone and quetiapine, respectively. Olanzapine was also considered more effective than the other antipsychotic drugs evaluated, followed by risperidone. Quetiapine and ziprasidone reported equivalent results of effectiveness. Risperidone was dominated by olanzapine, but also dominated the other two drugs evaluated. Ziprasidone was considered as effective as quetiapine, but with a lower cost, it was also considered dominant over quetiapine (Table 3). The scatter plot has shown complete separation between olanzapine and risperidone due to the difference of effectiveness. There was a superposition of cost values, demonstrating that, in some trials, the relationship 
Table 3. Cost-effectiveness report between olanzapine, risperidone, quetiapine and ziprasidone in Brazil, 2014

\begin{tabular}{|c|c|c|c|c|c|c|}
\hline Strategy & $\begin{array}{c}\text { Cost } \\
\text { BRL (USD) }\end{array}$ & $\begin{array}{l}\text { Incremental cost } \\
\text { BRL (USD) }\end{array}$ & Effectiveness & $\begin{array}{l}\text { Incremental } \\
\text { Effectiveness }\end{array}$ & CER & ICER \\
\hline Olanzapine & $\begin{array}{l}\$ 2,102.80 \\
(\$ 951.49)\end{array}$ & - & 9.8 & - & $\begin{array}{l}\$ 214.06 \\
(\$ 96.86) \\
\end{array}$ & - \\
\hline Risperidone & $\begin{array}{l}\$ 2,113.70 \\
(\$ 956.43)\end{array}$ & $\begin{array}{l}\$ 10.80 \\
(\$ 4.89)\end{array}$ & 8 & -1.8 & $\begin{array}{l}\$ 264.01 \\
(\$ 119.46)\end{array}$ & Dominated \\
\hline Ziprasidone & $\begin{array}{l}\$ 3,072.70 \\
(\$ 1390.36) \\
\end{array}$ & $\begin{array}{r}\$ 969.90 \\
(\$ 438.87) \\
\end{array}$ & 7 & -2.8 & $\begin{array}{r}\$ 437.53 \\
(\$ 197.98) \\
\end{array}$ & Dominated \\
\hline Quetiapine & $\begin{array}{l}\$ 3,330.80 \\
(\$ 1507.15)\end{array}$ & $\begin{array}{l}\$ 1,228.00 \\
(\$ 555.66)\end{array}$ & 7 & -2.8 & $\begin{array}{c}\$ 474.05 \\
(\$ 214.50)\end{array}$ & Dominated \\
\hline
\end{tabular}

between olanzapine and risperidone was not of dominance. Ziprasidone and quetiapine were isolated of risperidone and olanzapine, but not of each other. The costeffectiveness relationship between ziprasidone and quetiapine varied between trials (Graph 1). Considering a null willingness-to-pay (WTP) for month of effective treatment, olanzapine was considered the optimal strategy in 51.8\% of the trials and risperidone in $48.2 \%$. Considering a WTP of 252.00 BRL (114.03 USD) per month of effective treatment, olanzapine was considered the optimal strategy in all trials. The null WTP means that a system would not be willing to pay anything for extra unit of effectiveness achieved with more effective strategies, which is not realistic. There is no consensus on the value of a month of effective treatment. Anyway, olanzapine was considered the optimal strategy under any WTP value. Ziprasidone and quetiapine were not considered cost-effective in comparison to risperidone and olanzapine in any trial (Graph 2).
The deterministic sensitivity analysis, presented as a tornado diagram between risperidone and olanzapine, showed that the parameter that is more representative for the ICER between the drugs is olanzapine's price of purchase, followed by the costs of hospitalization and cost of risperidone. It can be observed that the price of purchase of olanzapine is capable of modifying the cost-effectiveness relationship between olanzapine and risperidone, from a situation where olanzapine is dominant to a situation that the decision has to be taken according to the ICER (Graph 3). The values of ICER presented, although, indicate that olanzapine would probably be considered the most cost-effective drug anyway. The probabilistic sensitivity analysis (PSA) demonstrated that, considering a null WTP, risperidone would be considered the optimal strategy in $50.4 \%$ of the trials. By increasing the WTP, olanzapine would progressively became more cost-effective until it was considered optimal in 100\% of the trials at a WTP of 364,00 BRL (164.71 USD) per month of effective treatment (Graph 4).

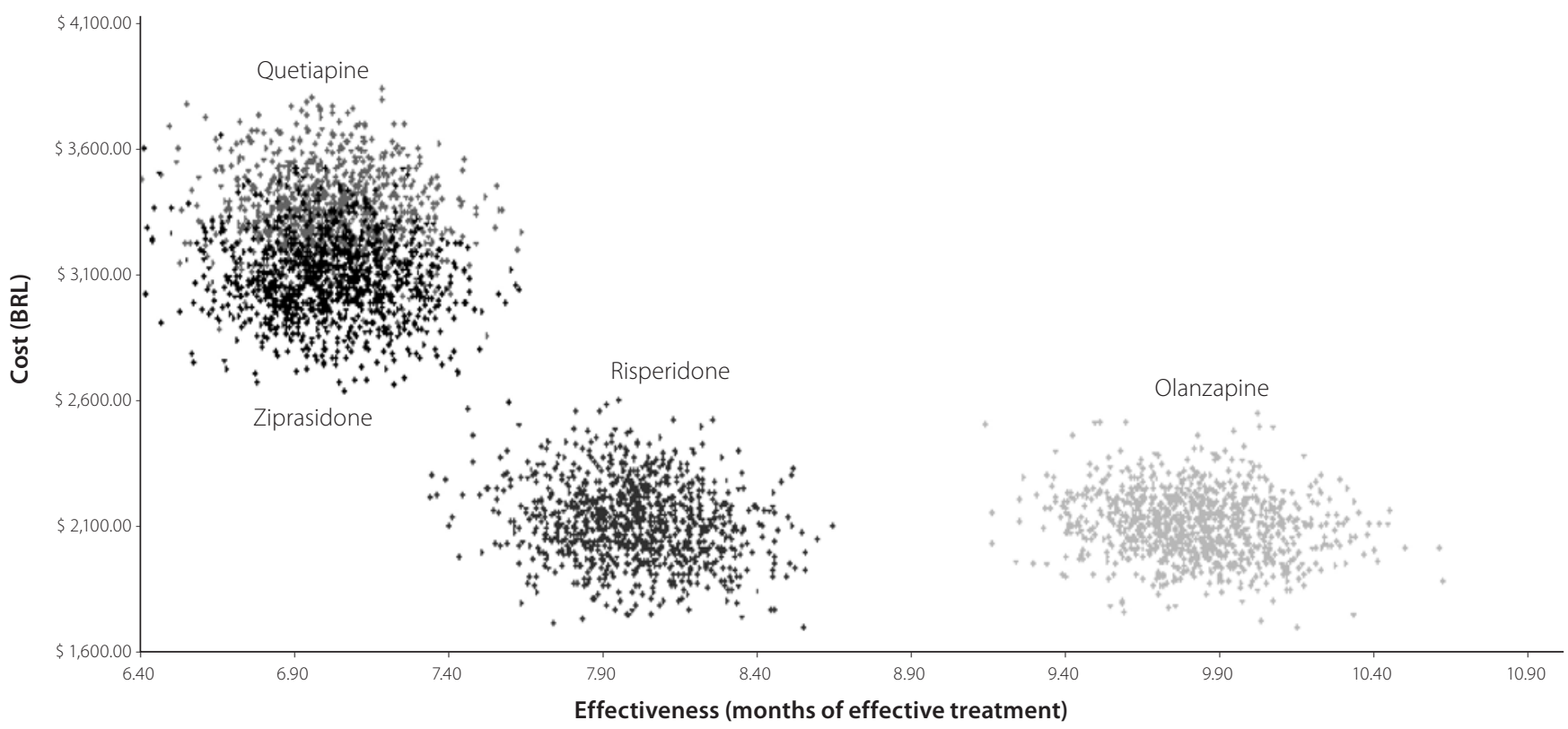

Graph 1. Scatter plot of the cost-effectiveness relationship between olanzapine, risperidone, ziprasidone and quetiapine in the Brazilian public health system, 2014. 


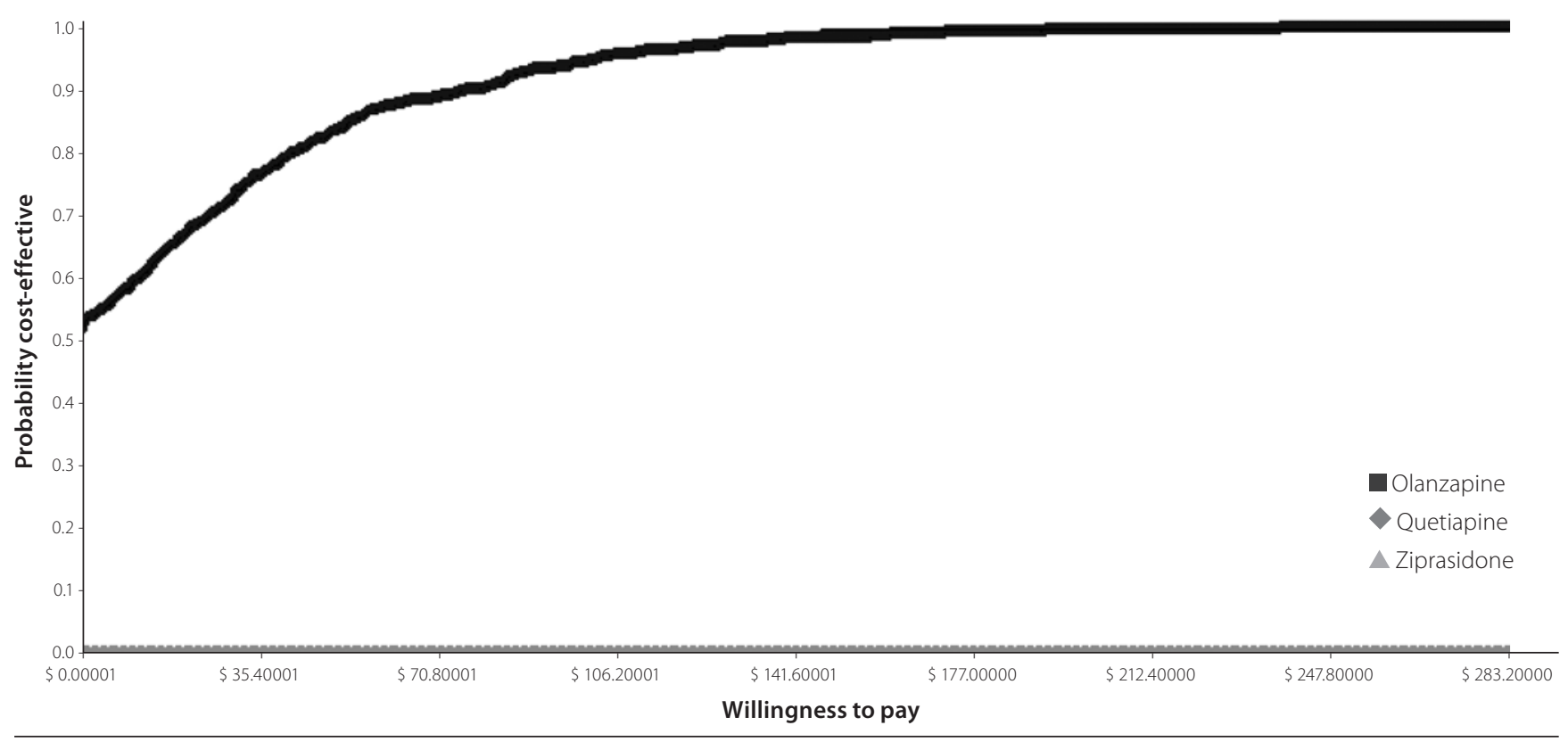

Graph 2. Acceptably curve between olanzapine, risperidone, quetiapine and ziprasidone. Risperidone was taken as base for the calculation, 2014.

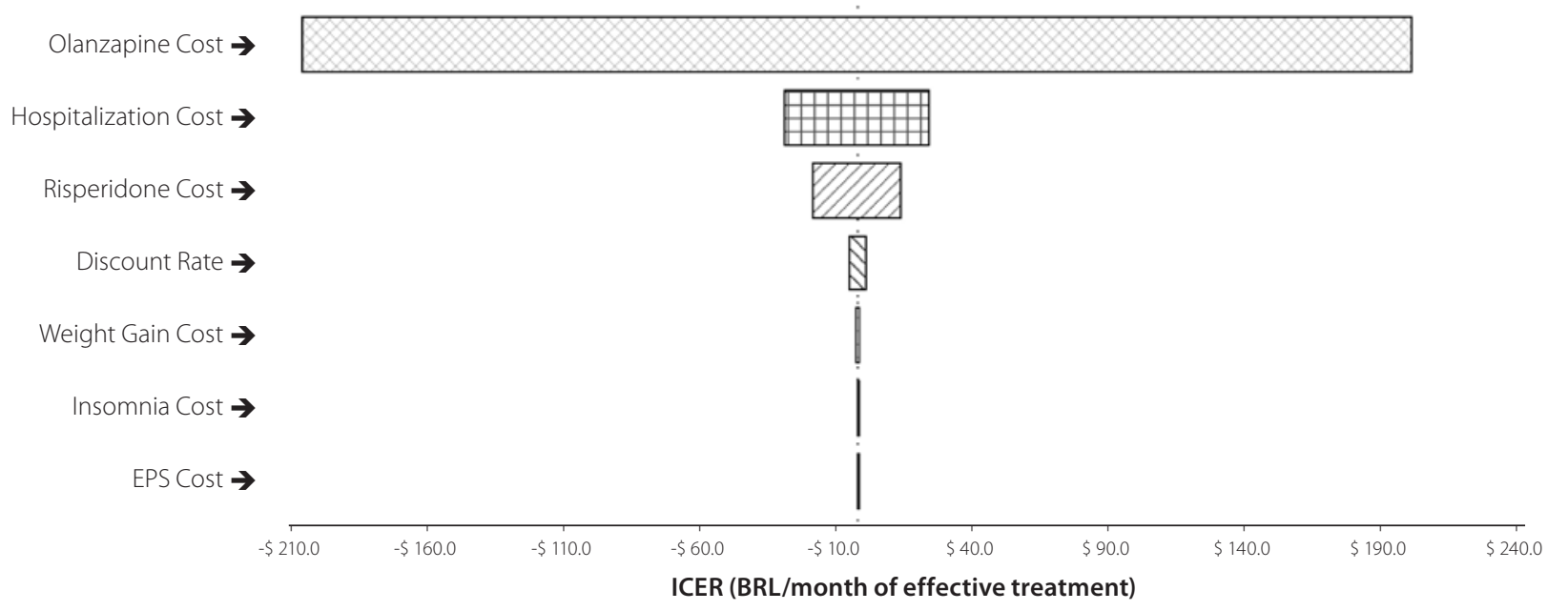

Graph 3. ICER Tornado Diagram between olanzapine and risperidone, 2014.

\section{Discussion}

Olanzapine was considered dominant over the other evaluated strategies. The analysis of the optimal choice indicated that olanzapine was considered optimal, considering a null WTP, in 51.8\% of the trials. Increasing values of WTP progressively makes the chance of olanzapine to be optimal increase, achieving 100\% at approximately 252.00 BRL (114.03 USD) per month of effective treatment. In the PSA, according to the uncertainty in cost variables, olanzapine was considered optimal in $49.6 \%$ of the trials, considering a null WTP. The chance of optimal choice of olanzapine achieved $100 \%$ at a WTP of $364,00 \mathrm{BRL}$ (164.71 USD) per month of effective treatment.
The results have shown the importance of the costs of prescription of olanzapine and hospitalization costs for the ICER between the drugs, as observed by Barbosa (2015). Olanzapine was considered optimal with any WTP threshold.

Other five head-to-head economic evaluations, conducted in USA, Greece and Norway, considered olanzapine to be dominant over risperidone (Rosenheck et al., 2006; Tunis et al., 2006; Geitona et al., 2008; Furiak et al., 2009; Kim \& Aas 2011). Six studies, conducted in USA, Canada, Mexico, Sweden and Vietnam, found risperidone to be dominant over olanzapine (Bounthavong \& Okamoto 2007; Cooper et al., 2008; MouldQuevedo et al., 2009; Mclntyre et al., 2010; Lindström et al., 2011; Anh et al., 2015). Other papers, from Slovenia, Canada, 


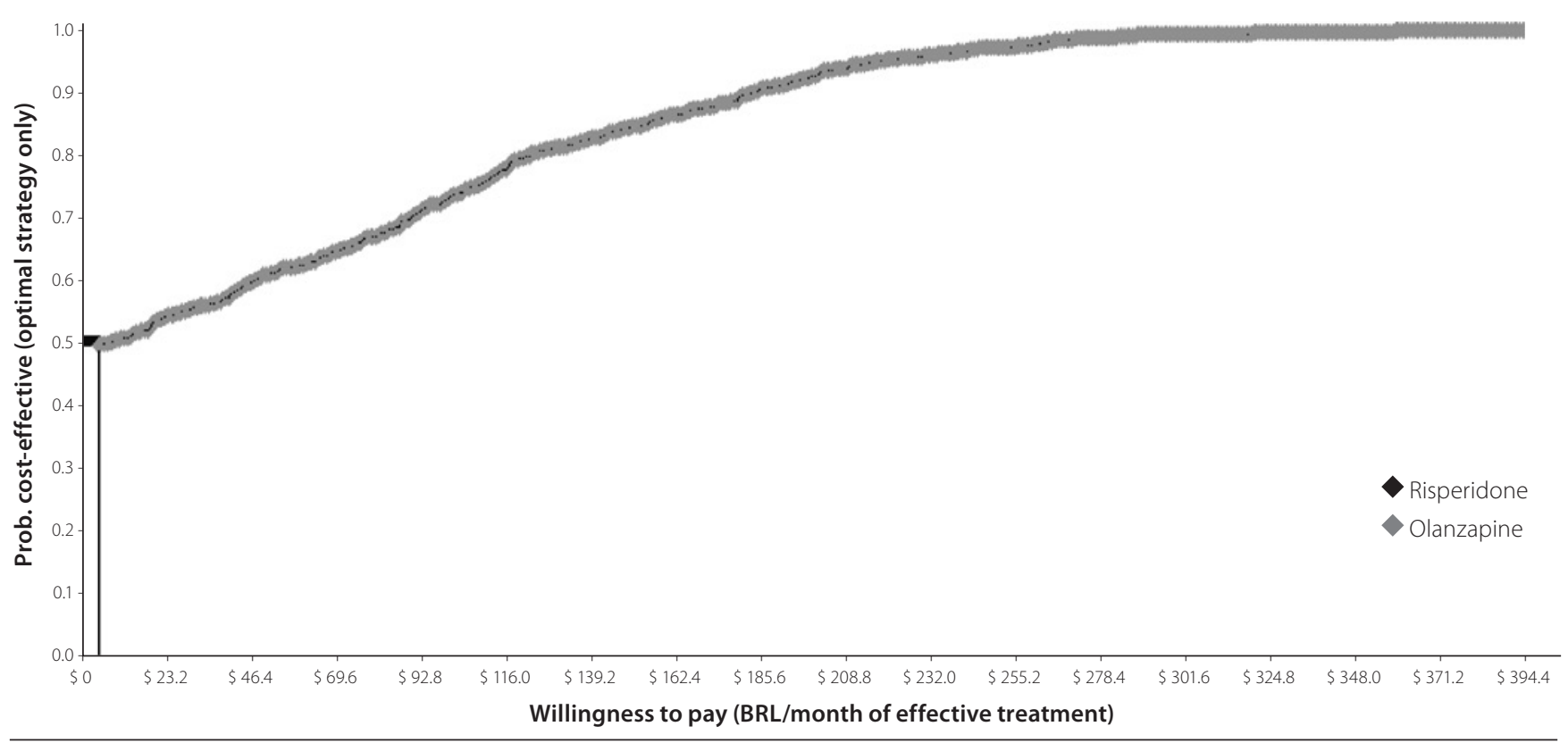

Graph 4. Probabilistic Sensitivity Analysis between olanzapine, risperidone, quetiapine and ziprasidone, 2014.

USA, Belgium, Brazil, Spain and Germany, reported data that favor olanzapine or risperidone in the ICER analysis, depending on the WTP in the place of study (Obradovic et al., 2007; Cooper et al., 2008; Edwards et al., 2008; Knapp et al., 2008; De Ridder \& De Graeve 2009; Lindner et al., 2009; Ascher-Svanum et al., 2012; Garcia-Ruiz et al., 2012; O'Day et al., 2013; Zeidler et al., 2013). Only one other study conducted in Brazil evaluated the cost-effectiveness relationship between olanzapine and risperidone, and considered risperidone to be the optimal choice due to the high ICER of 1.329.394,88 US\$/QALY found (Lindner et al., 2009).

Literature data are controversial in specify which drug is the most cost-effective between olanzapine and risperidone. Analyses favoring both drugs can be found. These analyses, however, vary in terms of outcomes, identified costs, model design, time horizon and data sources. Some authors suggest that the private funding of scientific work may be introducing bias in the analyses (Lexchin et al., 2003; Bero et al., 2007; Sismondo, 2008). Heres et al. (2006) observed that in head-to-head comparisons of antipsychotics, $90 \%$ of the papers present results that favors the sponsor. But with respect to the comparison of olanzapine and risperidone, there are non-funded studies that show results favoring one drug or the other (Rosenheck et al., 2006; Bounthavong \& Okamoto 2007; Obradovic et al., 2007; Lindner et al., 2009; Kim \&Aas 2011; Anh et al., 2015). Prospective design studies had difficulty to demonstrate significant difference between risperidone and olanzapine in terms of costs and outcomes. Apparently, this difficulty is associated to small samples, small real differences between the drugs and incapacity of the measurement instruments to capture small differences (Rosenheck et al., 2006; Tunis et al., 2006; De Ridder \& De Graeve 2009). Studies that evaluate primarily discontinuation of treatment tend to favor olanzapine (Lieberman et al., 2005; Stroup et al., 2006; Stroup et al., 2007; Kahn et al., 2008). Hospitalizations and relapses are important direct costs of schizophrenia. Drugs that provide a decrease in the chance of hospitalization may show economic advantage over the others (Genduso \& Haley 1997; Jones et al., 2006; Daltio et al., 2007). The prescription costs of olanzapine are higher when compared to risperidone, but the treatment costs can be influenced by the costs of hospitalization and treatment of adverse events, favoring olanzapine (Rosenheck et al., 2006; Tunis et al., 2006; Bounthavong \& Okamoto, 2007; Obradovic et al., 2007; Geitona et al., 2008; Furiak et al., 2009; Ascher-Svanum et al., 2012).

Comparing olanzapine to quetiapine or ziprasidone, the international analyses tend to favor olanzapine, as observed. Five papers, from Slovenia, Greece and USA, considered olanzapine dominant over quetiapine (Obradovic et al., 2007; Geitona et al., 2008; Knapp et al., 2008; Furiak et al., 2009; O'Day et al., 2013). Only one study, from Canada and funded by Pfizer, found quetiapine to be dominant over olanzapine (McIntyre et al., 2010). Other studies, conducted in USA, China and Germany, reported ICER results that, in general, favor olanzapine (Rosenheck et al., 2006; Edwards et al., 2008; Yang et al., 2009; Zeidler et al., 2013). Five studies, from Slovenia, USA and Greece, found olanzapine to be dominant over ziprasidone (Rosenheck et al., 2006; Obradovic et al., 2007; Edwards et al., 2008; Geitona et al., 2008; Furiak et al., 2009). Two studies, conducted in Mexico and Canada and sponsored by Pfizer, considered ziprasidone dominant over olanzapine (Mould-Quevedo et al., 2009; McIntyre et al., 2010) 
and one study found ziprasidone to be less effective and less costly, with ICER that favored olanzapine (O'Day et al., 2013). There is consistent evidence that olanzapine provokes more metabolic effects than other antipsychotic drugs (McQuade et al., 2004; Breier et al., 2005; Lieberman et al., 2005; Chiu et al., 2006; Rosenheck et al., 2006; Fleischhacker et al., 2009; Kane et al., 2009; Alvarez et al., 2012; Ou et al., 2013; Zhang \& Lan 2014). In general, analyses that focus on the metabolic profile of the drugs tend to disfavor olanzapine in comparison to other medication (Colombo et al., 2008; Mclntyre et al., 2010). Observational prospective design work also tends to disfavor olanzapine (Cooper et al., 2008; De Ridder \& De Graeve 2009). That happens due to olanzapine to be considered as a third option for the treatment of schizophrenia in some algorithms for its worse metabolic profile. Anyway, a cohort-based economic analysis funded by Eli Lilly found advantage for olanzapine in comparison to quetiapine and risperidone (Knapp et al., 2008).

Risperidone was found to be dominated by olanzapine, but was also considered dominant over the other drugs. The international cost-effectiveness analyses consistently favor risperidone over quetiapine and ziprasidone. Six studies, conducted in Slovenia, USA, Greece and Canada, reported dominance of risperidone over quetiapine (Obradovic et al., 2007; Edwards et al., 2008; Geitona et al., 2008; Furiak et al., 2009; McIntyre et al., 2010; O'Day et al., 2013) and three studies, from USA, Germany and Europe, reported lower costs and effectiveness for risperidone (Rosenheck et al., 2006; Knapp et al., 2008; Zeidler et al., 2013). Five papers, from Slovenia, USA and Greece, reported dominance of risperidone over ziprasidone (Obradovic et al., 2007; Edwards et al., 2008; Geitona et al., 2008; Furiak et al., 2009; O'Day et al., 2013). One study, conducted in Mexico and sponsored by Pfizer, considered risperidone dominated by ziprasidone (MouldQuevedo et al., 2009). Two other papers, from Canada and USA, reported lower costs and effectiveness for risperidone in comparison to ziprasidone. One of these was funded by Pfizer and presented results that favored risperidone (Rosenheck et al., 2006; Mclntyre et al., 2010), but did not use that result in the conclusion.

The results of effectiveness were found to be equivalent between ziprasidone and quetiapine. However, the total cost of ziprasidone treatment were considered inferior, indicating the dominance of ziprasidone over quetiapine as well. The evaluation of the international evidence tends to favor ziprasidone over quetiapine, in a qualitative analysis. Four papers, from USA, Slovenia and Canada, presented results indicating the dominance of ziprasidone over quetiapine (Obradovic et al., 2007; Furiak et al., 2009; Mclntyre et al., 2010; O'Day et al., 2013). Two studies, conducted in USA, found quetiapine to be dominant over ziprasidone (Rosenheck et al., 2006; Edwards et al., 2008) and one, conducted in Greece, found quetiapine to be more effective and costly, with ICER favoring ziprasidone (Geitona et al., 2008). In general, ziprasidone is only shown to be cost-effective compared to olanzapine and risperidone in studies sponsored by Pfizer. Ziprasidone leads to worse efficacy outcomes than risperidone and olanzapine, but it provokes less weight gain and cholesterol increase than olanzapine, risperidone and quetiapine (Komossa et al., 2009) that can be of interest to treat schizophrenic patients with dyslipidemia, hypertension, overweight and metabolic syndrome. Quetiapine is also found to be inferior to other SGAs in terms of efficacy; however, it provokes less movement disorders, weight gain and glucose increase than olanzapine, less movement disorders and prolactin elevation than risperidone and less extrapyramidal effects and prolactin elevation than ziprasidone (Asmal et al., 2013). These characteristics can be useful for specific groups of patients, justifying its use in lower levels, as reported by Barbosa (2015). The author observed that, in Brazil, between 2000 and 2010, risperidone was the most prescribed SGA (37\%), followed by olanzapine (35\%), quetiapine (16\%), ziprasidone (8\%) and clozapine (5\%).

Economic models are subjected to limitations associated with imprecision and bias, quality of the data source, impossibility to assess all clinical aspects of a scenario and the skepticism of the health professionals (Revicki, 1997). The time horizon of 18 months is too short to evaluate the future costs of metabolic effects and to discuss the long-term effectiveness of the drugs. There is no assurance that the short-term results of efficacy and effectiveness studies would represent the long-term effectiveness of antipsychotics (Garcia-Ruiz et al., 2012). The high occurrence of discontinuation of treatment is already an indicator that the effectiveness of the drugs is limited. Patients on olanzapine showed the lower level of discontinuation between the evaluated drugs and also the lower rate of hospitalization, which leads to the conclusion that it might be the most effective SGA analyzed (Lieberman et al., 2005). The cost of the treatment of obesity was extracted from the work of Oliveira (2013) that reported data from the Brazilian Ministry of Health. The costs absorbed by state and local health departments were not evaluated. The prescription costs, calculated through the values reported in BPS, may not be the best representation of the real value paid by state health departments because of the low number of purchases registered. It would not be realistic to imagine that after the first discontinuation of treatment the patient would not use another drug, but we stopped the model there so the analysis of the main drugs did not get damaged by other drugs data.

The cost of prescription of olanzapine are high when compared to risperidone, however, due to the lower probability of hospitalization and favorable adverse effects profile, the total costs of the olanzapine treatment are lower. Ziprasidone and quetiapine costs were also considered high when compared to olanzapine, mainly due to the high costs of prescription 
and hospitalization. Olanzapine was considered more effective than the other evaluated drugs. In conclusion, olanzapine was found to be the dominant strategy for the treatment of schizophrenia when compared to risperidone, quetiapine and ziprasidone, in Brazil. However, sensitivity analysis has shown that the cost-effectiveness relationship between olanzapine and risperidone can be modified by the price of purchase of olanzapine, leaving the decision of optimality to the ICER and WTP analysis. Due to the low values of ICER showed in the sensitivity analysis and PSA, olanzapine can be considered the most cost-effective strategy evaluated.

\section{Acknowledgements}

This study was conducted with operational support of Fundação Hospitalar do Estado de Minas Gerais (FHEMIG) and Grupo de Pesquisa de Farmacoepidemiologia of UFMG. It was funded by the Brazilian research promoting organizations Conselho Nacional de Desenvolvimento Científico e Tecnológico (CNPq) and Fundação de Amparo à Pesquisa do Estado de Minas Gerais (FAPEMIG). No pharmaceutical industries contributed with any resources. The authors declare to have no conflicts of interest that could influence the results of this study.

\section{References}

Alvarez E, Bernardo M, Casares JRG, Montejo AL. Ziprasidone versus olanzapine in the weight gain associated with the treatment of schizophrenia: A six-month double-blind randomized parallel group study. Eur J Psychiat. 2012;26(4):248-59.

American Psychiatric Association (APA). Diagnostic and Statistical Manual of Mental Disorders fourth edition (DSM-IV). Washington, American Psychiatric Association, 1994.

American Psychiatric Association (APA). Diagnostic and Statistical Manual of Mental Disorders fifth edition (DSM-5). Washington, American Psychiatric Association, 2013.

Anh NQ, Linh BN, Ha NT, Phanthunane P, Huong NT. Schizophrenia interventions in Vietnam: primary results from a cost-effectiveness stud. Glob Public Health. 2015;10 Suppl 1:S21-39.

Ascher-Svanum H, Furiak NM, Lawson AH, Klein TM, Smolen LJ, Conley $R R$, et al. Cost-effectiveness of several atypical antipsychotics in orally disintegrating tablets compared with standard oral tablets in the treatment of schizophrenia in the United States. J Med Econ. 2012;15(3):531-47.

Asmal L, Flegar SJ, Wang J, Rummel-Kluge C, Komossa K, Leucht S. Quetiapine versus other atypical antipsychotics for schizophrenia. Cochrane Database of Systematic Reviews. 2013.

Barbosa WB. Gastos com antipsicóticos atípicos, serviços ambulatoriais e hospitalares no tratamento da esquizofrenia: uma coorte de onze anos no Brasil. Belo Horizonte: Universidade Federal de Minas Gerais [Dissertation], 2015.

Behan C, Kennelly B, O'Callaghan E. The economic cost of schizophrenia in Ireland: a cost of illness study. Irish J Psychol Med. 2008;25(3):80-7.

Bero L, Oostvogel F, Bacchetti P, Lee K. Factors associated with findings of published trials of drug-drug comparisons: why some statins appear more efficacious than others. PLoS Med. 2007;4(6):e184.
Bounthavong M, Okamoto MP. Decision analysis model evaluating the cost-effectiveness of risperidone, olanzapine and haloperidol in the treatment of schizophrenia. J Eval Clin Pract. 2007;13(3):453-60.

Brandão CMR, Guerra-Jr AA, Cherchiglia ML, Andrade EIG, Almeida AM, Silva GD, et al. Gastos do Ministério da Saúde do Brasil com Medicamentos de Alto Custo: Uma Análise Centrada no Paciente. Value Health. 2011;14(5):S71-7.

Brazil. Diretrizes Metodológicas: estudos de avaliação econômica de tecnologias em saúde. Brasília, Ministério da Saúde, 2009.

Brazil. Portaria no. 364, de 9 de abril de 2013. M. d. Saúde. Brasília: Imprensa Nacional, 2013.

Breier A, Berg PH, Thakore JH, Naber D, Gattaz WF, Cavazzoni P, et al. Olanzapine versus ziprasidone: results of a 28-week double-blind study in patients with schizophrenia. Am J Psychiatry. 2005;162(10):1879-87.

Chiu CC, Chen KP, Liu HC, Lu ML. The early effect of olanzapine and risperidone on insulin secretion in atypical-naıve schizophrenic patients. J Clin Psychopharmacol. 2006;26(5):504-7.

Colombo GL, Caruggi M, Di Matteo S, Rossi A. An economic evaluation of aripiprazole vs olanzapine adapted to the Italian setting using outcomes of metabolic syndrome and risk for diabetes in patients with schizophrenia. Neuropsychiatr Dis Treat. 2008;4(5):967-76.

Cooper D, Moisan J, Abdous B, Grégoire JP. A population-based costeffectiveness analysis of olanzapine and risperidone among ambulatory patients with schizophrenia. Can J Clin Pharmacol. 2008;15(3):e385-97.

Daltio CS, Mari JJ, Ferraz MB. Overview about pharmacoeconomics analysis and burden-of-illness in schizophrenia. Rev Psiquiatr Clín. 2007;34(supl.2):208-12.

Davies LM, Lewis S, Jones PB, Barnes TR, Gaughran F, Hayhurst K, et al.; CUtLASS team. Cost-effectiveness of first- $v$. second-generation antipsychotic drugs: results from a randomised controlled trial in schizophrenia responding poorly to previous therapy. Br J Psychiatry. 2007;191:14-22.

De Ridder A, De Graeve D. Comparing the cost effectiveness of risperidone and olanzapine in the treatment of schizophrenia using the net-benefit regression approach. Pharmacoeconomics. 2009;27(1):69-80.

Edwards NC, Pesa J, Meletiche DM, Engelhart L, Thompson AK, Sherr J, et al. One-year clinical and economic consequences of oral atypical antipsychotics in the treatment of schizophrenia. Curr Med Res Opin. 2008;24(12):3341-55.

Fleischhacker WW, McQuade RD, Marcus RN, Archibald D, Swanink R, Carson WH. A double-blind, randomized comparative study of aripiprazole and olanzapine in patients with schizophrenia. Biol Psychiatry. 2009;65(6):510-7.

Furiak NM, Ascher-Svanum H, Klein RW, Smolen LJ, Lawson AH, Conley RR, et al. Cost-effectiveness model comparing olanzapine and other oral atypical antipsychotics in the treatment of schizophrenia in the United States. Cost Eff Resour Alloc. 2009;7:4.

Garcia-Ruiz AJ, Perez-Costillas L, Montesinos AC, Alcalde J, Oyaqüez I, Casado MA. Cost-effectiveness analysis of antipsychotics in reducing schizophrenia relapses. Health Econ Rev. 2012;2(1):8.

Geitona M, Kousoulakou H, Ollandezos M, Athanasakis K, Papanicolaou S, Kyriopoulos I. Costs and effects of paliperidone extended release compared with alternative oral antipsychotic agents in patients with schizophrenia in Greece: a cost effectiveness study. Ann Gen Psychiatry. 2008;7:16.

Genduso LA, Haley JC. Cost of illness studies for schizophrenia: components, benefits, results, and implications. Am J Manag Care. 1997;3(6):873-7.

Heres S, Davis J, Maino K, Jetzinger E, Kissling W, Leucht S. Why olanzapine beats risperidone, risperidone beats quetiapine, and quetiapine beats olanzapine: an exploratory analysis of head-to-head comparison studies of second-generation antipsychotics. Am J Psychiatry. 2006;163(2):185-94. 
Jones PB, Barnes TR, Davies L, Dunn G, Lloyd H, Hayhurst KP, et al. Randomized controlled trial of the effect on Quality of Life of second- vs first-generation antipsychotic drugs in schizophrenia: Cost Utility of the Latest Antipsychotic Drugs in Schizophrenia Study (CUtLASS 1). Arch Gen Psychiatry. 2006;63(10):1079-87.

Kahn RS, Fleischhacker WW, Boter H, Davidson M, Vergouwe Y, Keet IP, et al. Effectiveness of antipsychotic drugs in first-episode schizophrenia and schizophreniform disorder: an open randomised clinical trial. Lancet. 2008;371(9618):1085-97.

Kane JM, Osuntokun O, Kryzhanovskaya LA, Xu W, Stauffer VL, Watson SB, et al. A 28-week, randomized, double-blind study of olanzapine versus aripiprazole in the treatment of schizophrenia. J Clin Psychiatry. 2009;70(4):572-81.

Kim K, Aas E. Cost-effectiveness analysis of olanzapine and risperidone in Norway. J Ment Health Policy Econ. 2011;14(3):125-35.

Knapp M, Mangalore R, Simon J. The global costs of schizophrenia. Schizophr Bull. 2004;30(2):279-93.

Knapp M, Windmeijer F, Brown J, Kontodimas S, Tzivelekis S, Haro JM, et al. Cost-utility analysis of treatment with olanzapine compared with other antipsychotic treatments in patients with schizophrenia in the panEuropean SOHO study. Pharmacoeconomics. 2008;26(4):341-58.

Komossa K, Rummel-Kluge C, Hunger H, Schwarz S, Bhoopathi PS, Kissling W, et al. Ziprasidone versus other atypical antipsychotics for schizophrenia. Cochrane Database Syst Rev. 2009;(4):CD006627.

Lay B, Nordt C, Rössler W. Trends in psychiatric hospitalisation of people with schizophrenia: a register-based investigation over the last three decades. Schizophr Res. 2007;97(1-3):68-78.

Lexchin J, Bero LA, Djulbegovic B, Clark O. Pharmaceutical industry sponsorship and research outcome and quality: systematic review. BMJ. 2003:326(7400):1167-70.

Li YM, Zhao JP, Ou JJ, Wu RR. Efficacy and tolerability of ziprasidone vs. olanzapine in naive first-episode schizophrenia: a 6-week, randomized open-label, flexible-dose study. Pharmacopsychiatry. 2012;45(5):177-81.

Lieberman JA, Stroup TS, McEvoy JP, Swartz MS, Rosenheck RA, Perkins DO, et al. Effectiveness of antipsychotic drugs in patients with chronic schizophrenia. N Engl J Med. 2005;353(12):1209-23.

Lindner LM, Marasciulo AC, Farias MR, Grohs GE. Economic evaluation of antipsychotic drugs for schizophrenia treatment within the Brazilian Healthcare System. Rev Saude Publica. 2009;43 Suppl 1:62-9.

Lindström E, Eberhard J, Fors BM, Hansen K, Sapin C. A pharmacoeconomic analysis of sertindole in the treatment of schizophrenia in Sweden. Nord J Psychiatry. 2011;65(6):403-13.

Liu-Seifert H, Ascher-Svanum H, Osuntokun O, Jen KY, Gomez JC. Change in level of productivity in the treatment of schizophrenia with olanzapine or other antipsychotics. BMC Psychiatry. 2011;11:87.

Machado MA, Acurcio Fde A, Brandão CM, Faleiros DR, Guerra AA Jr, Cherchiglia ML, et al. Judicialization of access to medicines in Minas Gerais state, Southeastern Brazil. Rev Saude Publica. 2011:45(3):590-8.

Mari, JJ, Leitão RJ. A epidemiologia da esquizofrenia. Rev Bras Psiquiatr. 2000;22(suppl. 1):15-7.

McEvoy JP. The costs of schizophrenia. J Clin Psychiatry. 2007;68 Suppl 14:4-7.

McEvoy JP, Lieberman JA, Stroup TS, Davis SM, Meltzer HY, Rosenheck RA, et al. Effectiveness of clozapine versus olanzapine, quetiapine, and risperidone in patients with chronic schizophrenia who did not respond to prior atypical antipsychotic treatment. Am J Psychiatry. 2006;163(4):600-10.

McGrath J, Saha S, Chant D, Welham J. Schizophrenia: a concise overview of incidence, prevalence, and mortality. Epidemiol Rev. 2008;30:67-76.
McIntyre RS, Cragin L, Sorensen S, Naci H, Baker T, Roussy JP. Comparison of the metabolic and economic consequences of long-term treatment of schizophrenia using ziprasidone, olanzapine, quetiapine and risperidone in Canada: A cost-effectiveness analysis. J Eval Clin Pract. 2010;16(4):744-55

McQuade RD, Stock E, Marcus R, Jody D, Gharbia NA, Vanveggel S, et al. A comparison of weight change during treatment with olanzapine or aripiprazole: results from a randomized, double-blind study. J Clin Psychiatry. 2004;65 Suppl 18:47-56.

Messias EL, Chen CY, Eaton WW. Epidemiology of schizophrenia: review of findings and myths. Psychiatr Clin North Am. 2007;30(3):323-38.

Mould-Quevedo J, Contreras-Hernández I, Verduzco W, Mejía-Aranguré JM, Garduño-Espinosa J. Cost-effectiveness simulation analysis of schizophrenia at the Instituto Mexicano del Seguro Social: Assessment of typical and atypical antipsychotics. Rev Psiquiatr Salud Ment. 2009;2(3):108-18.

National Institute for Health and Care Excellence (NICE). Psychosis and schizophrenia in adults: treatment and management, 2014.

Newcomer JW, Ratner RE, Eriksson JW, Emsley R, Meulien D, Miller F, et al. A 24-week, multicenter, open-label, randomized study to compare changes in glucose metabolism in patients with schizophrenia receiving treatment with olanzapine, quetiapine, or risperidone. J Clin Psychiatry. 2009;70(4):487-99.

O'Day K, Rajagopalan K, Meyer K, Pikalov A, Loebel A. Long-term costeffectiveness of atypical antipsychotics in the treatment of adults with schizophrenia in the US. Clinicoecon Outcomes Res. 2013;5:459-70.

Obradovic M, Mrhar A, Kos M. Cost-effectiveness of antipsychotics for outpatients with chronic schizophrenia. Int J Clin Pract. 2007;61(12):1979-88.

Oliveira ML. Estimativa dos custos da obesidade para o Sistema Único de Saúde do Brasil. Brasília: Universidade de Brasília [Thesis], 2013.

Ou JJ, Xu Y, Chen HH, Fan X, Gao K, Wang J, et al. Comparison of metabolic effects of ziprasidone versus olanzapine treatment in patients with firstepisode schizophrenia. Psychopharmacology. 2013;225(3):627-35.

Park T, Kuntz KM. Cost-effectiveness of second-generation antipsychotics for the treatment of schizophrenia. Value Health. 2014;17(4):310-9.

Revicki DA. Methods of pharmacoeconomics evaluation of psychopharmacologic therapies for patients with schizophrenia. J Psychiatry Neurosci. 1997;22(4):256-66.

Riedel M, Müller N, Spellmann I, Engel RR, Musil R, Valdevit R, et al. Efficacy of olanzapine versus quetiapine on cognitive dysfunctions in patients with an acute episode of schizophrenia. Eur Arch Psychiatry Clin Neurosci. 2007;257(7):402-12.

Rodrigues LSM. Perfil e custos de hospitalização de pacientes com esquizofrenia no sistema único de saúde. Belo Horizonte: Universidade Federal de Minas Gerais [Dissertation], 2015.

Rosenheck RA, Leslie DL, Sindelar J, Miller EA, Lin H, Stroup TS, et al. Costeffectiveness of second-generation antipsychotics and perphenazine in a randomized trial of treatment for chronic schizophrenia. Am J Psychiatry. 2006;163(12):2080-9.

Sacchetti E, Valsecchi P, Parrinello G. A randomized, flexible-dose, quasinaturalistic comparison of quetiapine, risperidone, and olanzapine in the short-term treatment of schizophrenia: the QUERISOLA trial. Schizophr Res. 2008;98(1-3):55-65.

Shafti SS, Gilanipoor M. A Comparative Study between Olanzapine and Risperidone in the Management of Schizophrenia. Schizophr Res Treatment. 2014(2014):307202. 
Sirota P, Pannet I, Koren A, Tchernichovsky E. Quetiapine versus olanzapine for the treatment of negative symptoms in patients with schizophrenia. Hum Psychopharmacol. 2006;21(4):227-34.

Sismondo S. Pharmaceutical company funding and its consequences: a qualitative systematic review. Contemp Clin Trials. 2008;29(2):109-13.

Stroup TS, Lieberman JA, McEvoy JP, Swartz MS, Davis SM, Capuano GA, et al. Effectiveness of olanzapine, quetiapine, and risperidone in patients with chronic schizophrenia after discontinuing perphenazine: a CATIE study. Am J Psychiatry. 2007;164(3):415-27.

Stroup TS, Lieberman JA, McEvoy JP, Swartz MS, Davis SM, Rosenheck RA, et al. Effectiveness of olanzapine, quetiapine, risperidone, and ziprasidone in patients with chronic schizophrenia following discontinuation of a previous atypical antipsychotic. Am J Psychiatry. 2006;163(4):611-22.

Tiihonen J, Lönnqvist J, Wahlbeck K, Klaukka T, Niskanen L, Tanskanen A, et al. 11-year follow-up of mortality in patients with schizophrenia: a population-based cohort study (FIN11 study). Lancet. 2009;374(9690):620-7.

Tollefson GD, Birkett MA, Kiesler GM, Wood AJ. Double-blind comparison of olanzapine versus clozapine in schizophrenic patients clinically eligible for treatment with clozapine. Biol Psychiatry. 2001;49(1):52-63.
Tunis SL, Faries DE, Nyhuis AW, Kinon BJ, Ascher-Svanum H, Aquila R. Costeffectiveness of olanzapine as first-line treatment for schizophrenia: results from a randomized, open-label, 1-year trial. Value Health. 2006:9(2):77-89.

World Health Organization (WHO). Schizophrenia and public health. Geneva, World Health Organization, 1998.

Yang L, Li M, Tao LB, Zhang M, Nicholl MD, Dong P. Cost-effectiveness of long-acting risperidone injection versus alternative atypical antipsychotic agents in patients with schizophrenia in China. Value Health. 2009;12(Suppl 3):S66-9.

Zeidler J, Mahlich J, Greiner W, Heres S. Cost effectiveness of paliperidone palmitate for the treatment of schizophrenia in Germany. Appl Health Econ Health Policy. 2013;11(5):509-21.

Zhang S, Lan G. Prospective 8-week trial on the effect of olanzapine, quetiapine, and aripiprazole on blood glucose and lipids among individuals with first-onset schizophrenia. Shanghai Arch Psychiatry. 2014:26(6):339-46 